\title{
Combining ideal types of performance and performance regimes
}

\section{An integrated framework of analysis of performance management systems for public organizations}

Analysis of PMSs for public organizations

Received 28 November 2018 Revised 9 April 2019 Accepted 16 July 2019

\author{
Giorgio Giacomelli, Nora Annesi and Sara Barsanti \\ Institute of Management and Department EMbeDS, Scuola Superiore Sant'Anna, \\ Pisa, Italy, and \\ Massimo Battaglia \\ Department of Management, Sapienza University, Rome, Italy
}

\begin{abstract}
Purpose - The purpose of this paper is to contribute to the scholarship on public management models and to advance the theoretical conceptualization of the complexity of performance management systems (PMSs). The paper explores how the characteristics of PMSs vary within and across different organizational units in common institutional context, based on the case of a regional authority in Italy.

Design/methodology/approach - A framework of analysis considering both objective and subjective factors was derived from a combination of performance typologies in the public sector, namely ideal types of managing performance (Bouckaert and Halligan, 2007) and performance regimes (Jakobsen et al., 2017). The combination of the characteristics of these two models across different Directorates General (DGs) has also been explored through a nested case study (Starman, 2013). Data were gathered via a desk analysis of official documents regarding the planning and programming of a regional authority along with in-depth interviews with top-level managers.

Findings - The results highlighted a clear differentiation of PMSs, both within and across DGs. The findings of the study reveal the hybrid nature of PMSs within a common institutional context.

Originality/value - Drawing on the theoretical frameworks of Bouckaert and Halligan (2007) and Jakobsen et al. (2017), the paper provides an integrated approach for analysing PMSs, considering both objective and subjective dimensions. Insights and indications for future research on hybridity at a meso level of public organizations are highlighted.
\end{abstract}

Keywords Performance management systems, Performance ideal types, Performance regimes,

Public management

Paper type Research paper

Aim of the study

Public administrations, particularly those in western countries, have changed their organizational structures, routines and management styles shifting from traditional models derived from the Weberian approach (Dunleavy and Hood, 1994) to governance-like ones (Bovaird and Löffler, 2009). This trend has changed its dynamics both in time and space (Drechsler, 2010). In fact, even within the same country, scholars have highlighted a great variation with regard to the level and characteristics of the implementation of different public management models (Iacovino et al., 2015; Ongaro and Valotti, 2008).

(C) Giorgio Giacomelli, Nora Annesi, Sara Barsanti and Massimo Battaglia. Published by Emerald Publishing Limited. This article is published under the Creative Commons Attribution (CC BY 4.0) licence. Anyone may reproduce, distribute, translate and create derivative works of this article (for both commercial and non-commercial purposes), subject to full attribution to the original publication and authors. The full terms of this licence may be seen at http://creativecommons.org/licences/by/4.0/legalcode

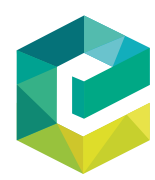

International Journal of Public Sector Management Emerald Publishing Limited DOI 10.1108/IJPSM-11-2018-0246 
Institutional crises tend to reveal the fuzziness of these dynamics and to emphasize differences in response to local contingencies, though some common reactions may be detected, such as a more centralized approach to decision making and greater political control over the civil service (Peters, 2011). Continual reforms result in complex public management models: features of previous models are not rejected, but rather complemented by characterizing instruments of the new ones, through a layering process (Christensen and Lægreid, 2011; Iacovino et al., 2015).

This paper explores how the simultaneous presence of multiple models impacts on public organizations at a meso level, with specific reference to the characteristics of the performance management systems (PMSs) of different units within a common institutional context. It is reasonable to expect that unclear configurations of PMSs may emerge, based on different combinations of specific factors (sectorial, administrative, organizational), even within a common institutional context.

In line with the stream of research that challenges a "doctrinal" approach to PMSs (Moynihan, 2008), this paper integrates theories on ideal types of management performance (Bouckaert and Halligan, 2007) and performance regimes (Jakobsen et al., 2017) in order to explore the presence of mixed combination of PMSs in a common institutional context. To this aim, a case study of a regional authority in Italy is presented and discussed, based on the analysis of qualitative data.

The paper is structured as follows. The second section provides some preliminary comments based on the literature on ideal types of managing performance and performance regimes. The third section presents the methodological issues. The results of the analysis are then reported in the fourth section. The fifth section discusses the results. Lastly, the conclusions and suggestions for further research are reported in the sixth section.

\section{Theoretical background}

Performance management is generally expected to enhance the rationality of policy-making and management (Van Dooren and Van de Walle, 2016) by exploiting an evidence-based approach. It is also expected to support effective multi-level governance.

A PMS is usually defined as the set of tools for defining performance, measuring and linking it to incentives and sanctions hierarchically provided, generally coupled with some degree of managerial autonomy (Ketelaar et al., 2007) and embedded within certain contextual schemes (O'Toole and Meier, 2015). PMSs improve management by providing strategic focus, useful metrics, goals and incentives, and they improve accountability by providing data on government performance (Forsythe, 2001). Despite such general goals and expectations, PMSs have experienced historically situated evolution, moving from traditional models aimed at appraising and controlling (individual) performance to alternative ones eliciting internal learning (IL) (group) processes (Brudan, 2010). Recent conceptualizations of PMSs tend to highlight the role of incentive schemes in supporting reflective work practices and motivating employees (Saunila et al., 2015), as a necessary response to evolving contextual demands (Greiling and Halachmi, 2013).

However, several scholars (De Bruijn, 2002; Fryer et al., 2009; Van Thiel and Leeuw, 2002) have also stressed the risks of performance management, such as gaming, deviant behaviours and increased internal bureaucracy, thus questioning a "normative" approach to performance management. In order to manage the various challenges to implementation, such as competing performance dimensions, rule constraints, organizational factors, inter-organizational factors, technical barriers and resource constraints related to the risks listed above (Wholey, 2002), some scholars have developed a theoretical discourse aimed at avoiding "one-size-fit-all" approaches (Ohemeng, 2010) by including contextual factors (O’Toole and Meier, 2015).

This has been mirrored by the production of several interpretative schemes for PMSs (Bouckaert and Halligan, 2007; Moynihan et al., 2011; Newcomer and Caudle, 2011; 
Lee Rhodes et al., 2012). These schemes tend to group recurring characteristics of existing cases into ideal models or archetypes, in line with what scholars usually do with regard to public management reforms (Liguori et al., 2016; Pollitt and Bouckaert, 2011). These models refer to different combinations of administrative values and ideas (Pollitt and Bouckaert, 2011), accordingly translated into organizational routines and tools. Although a significant body of literature has highlighted the convergence of public sector reforms, scholars have increasingly debated the factors by which general trends have been translated into local application, sometimes leading to hybrid configurations (Christensen and Lægreid, 2011).

The present study aims to illuminate how the characteristics of PMSs may vary within and across different organizational units in a common institutional context. In order to answer this research question, we develop a framework of analysis considering both objective and subjective factors, with the former referring to the characteristics of the organizational tools considered, and the latter referring to the nature of the relationships between the actors involved. For this purpose, we take into consideration and reconcile two theoretical typologies of PMSs, namely ideal types of managing performance (Bouckaert and Halligan, 2007) and performance regimes (Jakobsen et al., 2017). We present the main features of the two typologies and then propose a combined framework of analysis where they complement each other.

\section{Ideal types of managing performance}

According to Bouckaert and Halligan (2007), managing performance consists of measuring, incorporating and using performance information. This "logical sequence of collecting data, integration of data into the management systems and, finally, putting information at work" (Van Dooren et al., 2015, p. 6) leads to an information-decision continuum. The assumption underlying this definition is that performance measurement should be instrumental to its use, and it only becomes valuable when directed at managerial action.

Performance measurement is the systematic collection of performance-related data for a performance purpose. Incorporation refers to the transposition of these measures into organizational routines and procedures with the aim of influencing the organizational discourse. The use of performance information is affected by a great variety of drivers (Kroll, 2015; Moynihan and Pandey, 2010) and has many forms: from designing policies and allocating resources to assessing results and improving accountability.

Based on these premises, Bouckaert and Halligan identified four ideal types of managing performance: performance administration, management of performances, performance management and performance governance. These four models represent pure (ideal) types, corresponding to different articulations of the main components of performance (Table I),

\begin{tabular}{|c|c|c|c|c|}
\hline & $\begin{array}{l}\text { Performance } \\
\text { administration }\end{array}$ & $\begin{array}{l}\text { Managements of } \\
\text { performances }\end{array}$ & $\begin{array}{l}\text { Performance } \\
\text { management }\end{array}$ & $\begin{array}{l}\text { Performance } \\
\text { governance }\end{array}$ \\
\hline Measurement & $\begin{array}{l}\text { Administrative data } \\
\text { registration, objective, } \\
\text { mostly input and process }\end{array}$ & $\begin{array}{l}\text { Specialised } \\
\text { performance } \\
\text { measurement systems }\end{array}$ & $\begin{array}{l}\text { Hierarchical } \\
\text { performance } \\
\text { measurement } \\
\text { systems }\end{array}$ & $\begin{array}{l}\text { Consolidated } \\
\text { performance } \\
\text { measurement } \\
\text { system }\end{array}$ \\
\hline Incorporation & Limited & $\begin{array}{l}\text { Within different } \\
\text { systems for specific } \\
\text { management functions }\end{array}$ & $\begin{array}{l}\text { Systemically } \\
\text { internal } \\
\text { integration }\end{array}$ & $\begin{array}{l}\text { Systemically } \\
\text { internal and } \\
\text { external } \\
\text { integration }\end{array}$ \\
\hline Use & $\begin{array}{l}\text { Limited: reporting, } \\
\text { internal, single loop }\end{array}$ & $\begin{array}{l}\text { Disconnected policy } \\
\text { and management } \\
\text { cycles }\end{array}$ & $\begin{array}{l}\text { Coherent, } \\
\text { comprehensive, } \\
\text { consistent }\end{array}$ & Societal use \\
\hline
\end{tabular}

Source: Adapted from Bouckaert and Halligan (2007)

Analysis of PMSs for public organizations

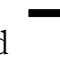


and the taxonomy assumes the existence of a trend pushing systems of performance from one stage to another.

In performance administration, a measurement system has a limited span and depth. It focusses on administrative data and mostly concerns input and processes. Incorporation is disconnected and variable, and there is limited use of performance information, mostly for internal reporting.

The management of performances ideal type consists of several loosely connected management fields. This results in a variety of performance measurement practices shaping different managerial improvement strategies. Feeding these management functions with a varied span of performance information results in different ways of incorporating this information, and this difference in incorporation fits different ways of using information. Its span of measurement encompasses inputs, process and outputs; there is also an awareness of managerial effectiveness within the organization (Vainieri et al., 2019), and therefore outcomes are also taken into account. Whereas the performance administration ideal type considers measurement systems as neutral, this model assumes that they influence the behaviour of those being measured, starting considering dysfunctional effects (Van Thiel and Leeuw, 2002).

The performance management ideal type is expected to pursue a coherent integration of measurement, incorporation and use of performance. Legitimacy is added as a criterion for a performance measurement system. The process of incorporation relies on quality models, and takes into account the need to match supply and demand. Using performance information includes a systematic comparison of results aimed at continuous improvement.

In the fourth ideal type, i.e. performance governance, measurement is characterized by a full span (including trust) and depth (extended to a systemic level). The level and degree of incorporation is hyperdynamic. The use of performance information overcomes the managerial and political domains, embracing external stakeholders (e.g. citizens), with reflection in reporting and accountability.

\section{Performance regimes}

The domain of performance regimes is greater than that of performance measurement and management and deals with the governance systems that rely on certain performance measurement practices (Moynihan et al., 2011). Performance regimes refer to specific combinations of external actors with the opportunity to steer the expected performance of public sector service delivery units (Talbot, 2008). Jakobsen et al. (2017) propose a conceptualization of performance regimes in public organizations where external actors are political and managerial superiors that use external goal setting and incentives. Starting from a critical review of the features of an external accountability (EA) regime, Jakobsen et al. introduce some contextual and individual variables in order to enrich the model and challenge the traditional regime for public administrations. By incorporating task complexity (Andrews and Boyne, 2014; Moynihan et al., 2011) and multifaceted motivation (Deci and Ryan, 2000), we present two more models, namely professional and IL regimes (Table II).

In terms of autonomy, in the EA regime, the setting of goals and measures is determined externally. On the opposite side of the spectrum, the professional regime allows for internally determined goals and measures tied to professional norms. In terms of incentives, the EA regime is driven by strong external incentives and targeted at EA, whereas the professional regime has no strong incentives and is directed to internal accountability that is achieved through internal fora.

Jakobsen et al. define the IL regime as a hybrid, where professionals are given "more goal autonomy in selecting goals and measures as a matter of deliberate design, thereby giving up complete political-bureaucratic control over goals" (p. 9). These characteristics of the IL regime create room for an accountability risk: when goals are set under reduced political control, a misalignment of the goals of employees and external stakeholders is likely to 


\begin{tabular}{|c|c|c|c|c|}
\hline & $\begin{array}{l}\text { External accountability } \\
\text { (EA) regime }\end{array}$ & Internal learning (IL) regime & Professional regime & $\begin{array}{l}\text { Analysis of } \\
\text { PMSs for }\end{array}$ \\
\hline $\begin{array}{l}\text { Goal } \\
\text { autonomy }\end{array}$ & $\begin{array}{l}\text { Low, External, tied to } \\
\text { political-bureaucratic goals }\end{array}$ & $\begin{array}{l}\text { Medium, Lower-level goals and } \\
\text { performance measures set by } \\
\text { professionals }\end{array}$ & $\begin{array}{l}\text { High, Goals are set by } \\
\text { professionals, tied to } \\
\text { professional values }\end{array}$ & organizations \\
\hline Incentives & External, high-powered & $\begin{array}{l}\text { Internal, aimed at norms, } \\
\text { values and peer status }\end{array}$ & Internal, low-powered & \\
\hline Accountability & $\begin{array}{l}\text { External with performance } \\
\text { focus }\end{array}$ & $\begin{array}{l}\text { Internal accountability } \\
\text { embedded within an external } \\
\text { regulative bargain and with } \\
\text { regular dialogue between } \\
\text { principals and agents }\end{array}$ & $\begin{array}{l}\text { Internal, tied to professional } \\
\text { norms (with a regulative } \\
\text { bargain) }\end{array}$ & \\
\hline $\begin{array}{l}\text { Rationale for } \\
\text { improvement }\end{array}$ & $\begin{array}{l}\text { Improvements through } \\
\text { external control and } \\
\text { incentives; controlled } \\
\text { motivation; learning about } \\
\text { goal achievement but not } \\
\text { goals (single-loop learning) }\end{array}$ & $\begin{array}{l}\text { Improvement through learning } \\
\text { spurred by autonomous } \\
\text { motivation } \\
\text { Learning on (lower-level) goals } \\
\text { and goal achievement infused } \\
\text { with values and experiences of } \\
\text { experts (single- and double- } \\
\text { loop learning) }\end{array}$ & $\begin{array}{l}\text { Improvement through new } \\
\text { professional expertise; } \\
\text { autonomous motivation; } \\
\text { learning on goals and goal } \\
\text { achievement through } \\
\text { professional norms and goals } \\
\text { (single- and double-loop } \\
\text { learning) }\end{array}$ & \\
\hline \multicolumn{4}{|c|}{ Source: Adapted from Jakobsen et al. (2017) } & Performance regimes \\
\hline
\end{tabular}

emerge; moreover, this may drive the adoption of less comparable measures by different organizations, with a potential loss in terms of EA.

Combining performance ideal types and performance regimes

Although for general management, Ferreira and Otley (2009) have provided a holistic framework of analysis for PMSs, to the best of our knowledge no specific typology has been proposed in the public sector to classify and interpret both the objective (e.g. span of performance) and subjective (e.g. actors involved in the goal-setting process) dimensions of PMSs. Several scholars have adopted and/or adapted Bouckaert and Halligan's typology, and stretched its domain in order to include further contextual dimensions such as administrative culture (Lee Rhodes et al., 2012). On the other hand, the application of Jakobsen et al.'s typology has recently grounded the investigation of public sector employees' coping behaviours (Van Loon and Jakobsen, 2018).

We try to advance public management scholarship by proposing a combined framework derived from the above-mentioned typologies. Since these two typologies have overlapping features (e.g. accountability), though different perspectives, we combine them in a common framework of analysis. This combined framework considers the following dimensions: measurement, incorporation, use (Bouckaert and Halligan, 2007), goal autonomy, incentives and rationale for improvement (Jakobsen et al., 2017). Accountability (Jakobsen et al., 2017) has been omitted since it is already incorporated as a sub-dimension of use (Bouckaert and Halligan, 2007).

\section{Methodology}

In order to address the objectives of this research, the study was conducted through a case study (Yin, 2017). The study investigates the organizational solutions adopted in a regional context, as a potentially comparative study among similar contexts, since this provides a valuable opportunity to explore PMSs and to advance the theoretical conceptualization of the complexity of PMSs, at an intermediate institutional level between national and local. In fact, Italy is divided into 20 geographical regions, each with 
its own regional administration. Each region is then further divided into provinces, with the most local level being municipalities.

The case describes a selection of ten Directorates Generals (DGs) of a regional authority which recently planned several actions aimed at reducing territorial variability in the performance of services, including a recentralization legislative intervention, bringing provision tasks back to the regional level for certain policy areas that had previously been delegated to the provincial level. The research group was involved in this process as external scientific experts, in order to contribute to the critical assessment of the existing PMSs of the different DGs.

As only line units tend to provide services that can be measured with a broad span of performance (ranging from inputs to outcomes), staff units such as "Organization and HR" (which are mostly concerned with internal services and processes) were included in the study only to complement the analysis when providing information about cross-cutting issues.

The study was conducted in two phases: a preparatory analysis of documents, the collection of information via semi-structured interviews with regional top managers. For both phases, we adopted a content analysis method (Graneheim and Lundman, 2004; Krippendorff, 2012; Morgan and Smircich, 1980). The content analysis consists of codifying pieces of writing into various items (or categories) depending on selected criteria. The categories were derived from an integrated framework of analysis considering dimensions of both ideal types of managing performance (Bouckaert and Halligan, 2007) and performance regimes (Jakobsen et al., 2017).

First, a review of selected regional documents was performed in order to identify declared goals, medium-long-term strategies and indicators. We selected those documents that referred to planning, programming and control issues at several levels and performed a content analysis in order to highlight key features of measurement and incorporation dimensions (Bouckaert and Halligan, 2007). The aim of this phase was to provide contextual information as an informative basis for the subsequent interviews. A total of 12 documents were reviewed: the Regional Development Plan, the Territorial Direction Plan, the Performance Plan along with several sectorial plans (Table III). Second, between January 2016 and April 2017, ten face-to-face in-depth interviews were conducted with the general directors and top managers of each DG.

Each interview was conducted in Italian by two researchers and with the support of a digital recorder, for a total amount of 22 interview-hours recorded, which were later transcribed verbatim. Each transcript was then validated by the interviewee.

In order to guide the discussion towards the integrated framework, so as to create an open discussion within defined boundaries (Denzin and Lincoln, 2005), a semi-structured protocol was defined and shared with the interviewees in advance. The protocol of the

Table III. $\quad 9$

Official planning and 10 programming 11 documents considered 12

\begin{tabular}{rll}
\hline No. & Name of the plan & Type of plan \\
\hline 1 & Regional Development Plan & General \\
2 & Territorial Programming Plan & General \\
3 & Performance Plan & General \\
4 & Regional Plan for Economic Development & Sectorial \\
5 & Regional Agroforestry Plan & Sectorial \\
6 & Regional Environmental and Energy Plan & Sectorial \\
7 & Regional Plan for the Quality of Air Environment & Sectorial \\
8 & Integrated Regional Plan for Infrastructures and Mobility & Sectorial \\
9 & Regional Plan for Culture & Sectorial \\
10 & Integrated Regional Plan for Health & Sectorial \\
11 & Integrated Regional Plan for Immigration Policies & Sectorial \\
12 & Integrated Regional Plan for International Activities & Sectorial \\
\hline
\end{tabular}


interview was structured in four sections devoted to the identification of: mission and activity, methods of integrating the objectives of policy makers, current monitoring system and available data and every day work and routines. For each section, a set of three to four questions was outlined.

Following Krippendorff (2012), a content analysis was performed on interview transcripts in order to highlight, for each section of the protocol, the key features of measurement, incorporation, use (Bouckaert and Halligan, 2007), goal autonomy, incentives and rationale for improvement (Jakobsen et al., 2017).

We used a constant comparison method (Glaser, 1965) and coded the collected materials using Nvivo software in order to systematically examine each interview, based also on recurrent words and keywords. All interviews were coded using a common structure (Glaser, 1965); this led to a coherent and comparable tree of nodes for each interview. Each node was explored among DGs by word frequency, in order to identify the most frequent words related to the six dimensions of analysis, and by additional keywords selected by the researchers. We thus obtained six groups of frequent words and additional keywords, each group corresponding to a specific dimension of the framework of analysis. Details on the structure of the text analysis are provided in Table A1.

Data sorting and the in-depth analysis highlighted recurrent characteristics and emerging relations among themes, thus enabling subsequent conceptualizing (Taylor et al., 2015). Though unavoidably affected by a certain level of subjectivity (Locke and Lloyd-Sherlock, 2011), the in-depth textual analysis enriched the understanding of the regional authority's organizational specificities. This step also highlighted the main connections between the protocol of the interviews and the framework of analysis (Figure 1). In order to reduce subjectivity bias, results were separately discussed by the two members of the research group and, when divergent, were discussed and confirmed by a third person in order to enhance the soundness of the interpretation (Denzin and Lincoln, 2005).

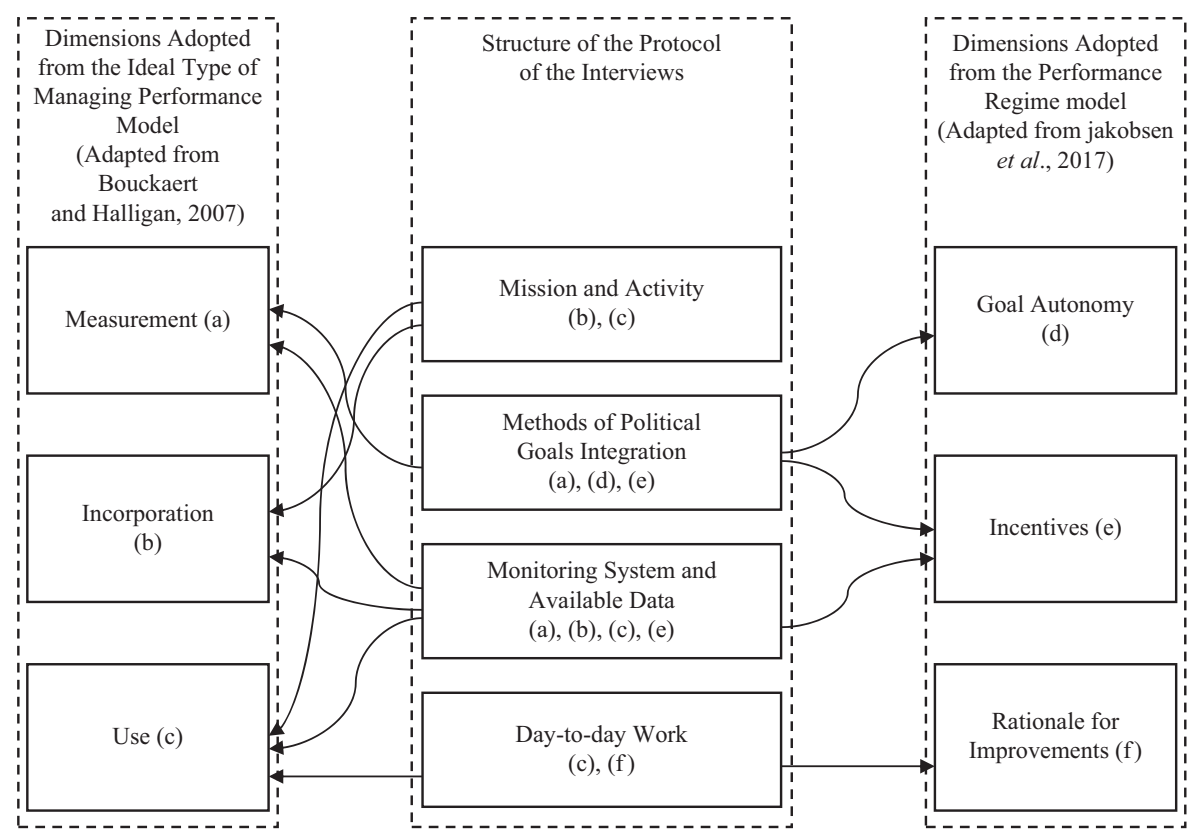

Analysis of PMSs for public organizations

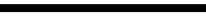

Figure 1.

Main content connections emerging between the protocol of the interviews and performance ideal types (Bouckaert and Halligan, 2007) and performance regimes (Jakobsen et al., 2017) 


\section{Results}

\section{Description of the case}

The regional authority is located in a region of central Italy counting about $3.7 \mathrm{~m}$ inhabitants. With a relative weight of the 6.8 per cent of the national GDP and the 7 per cent of the national export, the considered region is ranked above the national average level by the Regional Competitiveness Index (Annoni et al., 2017).

The organization of the regional authority is coordinated by a General Manager, below whom there are 14 DGs, the Attorney General and the Cabinet office of the President of the Region. Following a national reform that led to the merger of some provincial functions (i.e. Law 2014/56), in 2015 several regional DGs underwent a process of recentralization of the previously delegated provision function. At the beginning of 2016, about a quarter of workers employed in the provinces, the metropolitan city and the consortiums of the municipalities were absorbed into the regional authority. In order to ease the process of incorporating the previously provincial functions and integrate employees with different backgrounds, the regional authority has its own package of management controls (Malmi and Brown, 2008), such as monitoring tools, common regulations and training interventions.

The institutional story of the regional authority is one of overall good performance. According to the Quality of Government index (Charron et al., 2014), which is meant to measure the institutional capacity of governments to deliver quality policies, the region has been ranked systematically above the Italian national average, though significantly below the European average. All in all, these data seem to tell a case of good institutional capacity within the specific territorial context in which it is located (Charron and Lapuente, 2018).

Our research group was involved as external scientific experts to aid the General Manager in the comparative assessment of the PMSs of the DGs and the design of benchmarking-like tools. The case describes the results of the analysis of the PMSs of ten DGs of the regional authority, which are then analysed based on our proposed framework.

Below we review the features of the PMSs of all DGs considered in the light of the proposed framework of analysis. We thus describe the emerging trends and specificities regarding goal autonomy, measurement, incentives, incorporation, use and rationale for improvement. As a result of this process, a comparative table is provided and discussed (Table IV).

\section{Goal autonomy}

The frame for goal definition generally appears to be linked to external political and managerial forces and is characterized by a low level of autonomy. Except for two DGs (Mobility and Infrastructure DG and Welfare and Health DG), the model can be linked to the EA regime and conveys the idea that performance improvements are driven by "external" political-bureaucratic initiatives. For instance, regarding goal definition of Education and Training DG, one interviewee reported that:

$[\ldots]$ the political stance was very clear at the beginning of the legislature [...]: this orientation is now being translated into reform action, which goes through the process of reviewing the priorities of the regional government and, therefore, the definition of various actions. This, among other things, is a direction towards which also the central level - i.e. the Ministry - is pushing very much and towards which we must also converge as a regional administration. (Education and Training DG)

This can be interpreted under the lens of crisis management (Peters, 2011). Our content analysis of both official documents and interviews highlighted a trend towards centralization affecting decision making across several branches of the Regional Authority: frequently the interviewees explained that goals are usually set according to a top-down process:

Some of the priority objectives that we have put into our program derive directly from regional programs, which are therefore a political indication of a higher level. Based on this, several 


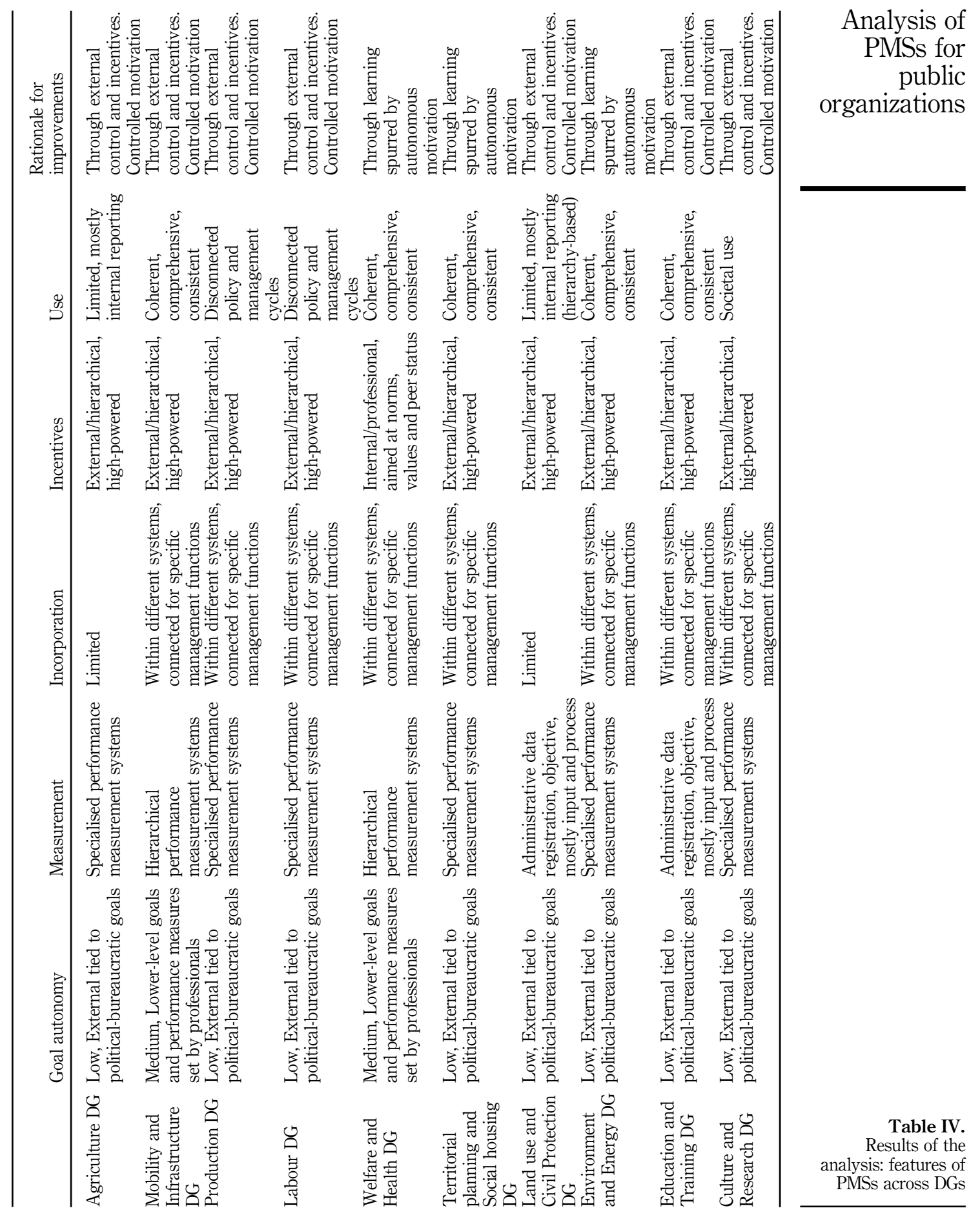


priorities are identified, which are shared with the regional Government through the Commissioner and the President. (Agriculture DG)

Our goals are basically a conceptual derivation of the political ones. (Land Use and Civil Protection DG)

Features that can be related to an alternative model, namely IL regime, can be traced back to the Mobility and Infrastructure DG and the Welfare and Health DG. Whereas the first case can be explained by specific organizational and technical factors, the latter needs to be read in the context of the professionalized nature of the service. Knowledge-intensive organizations (Mintzberg, 1989; Von Nordenflycht, 2010) usually present an "inverted power structure" in which professionals have greater influence over decision making on a day-to-day basis than staff in positions of hierarchical authority (Dickinson et al., 2016), thus leading to a redefinition of the power balance:

We actually already manage this [goals] negotiation process with all our directors and managers, and then we make a counterproposal and discuss it with the Secretary of the Government. Again, our difficulty is to coordinate these goals [...]; I guess others [DGs] do not have a situation like ours. I have to be sure that the Performance Plan is consistent both with the planning of the Regional Health Agency and the planning of the [health] authorities. (Welfare and Health DG)

\section{Measurement}

When considering measurement, the Regional Authority's DGs tend to swing between performance administration and management of performances ideal types (Bouckaert and Halligan, 2007). A general vertical coherence seems to emerge, and this can be detected in a broad span of performance (including input, process, quality, output), together with a linkage among measures at different levels of depth. Though most DGs have measures that are specialized, technically valid and functional for performance, some of them (e.g. Land use and Civil Protection, Education and Training) still present features that can be connected to a more restricted model and shrinking span of performance. Measurement, in these DGs, concentrates mostly on input, process and volumes (e.g. number of weather alerts received and passed, amount of money assigned for nursery schools) and presents a silo mentality:

The targets on which we are asked to account for to the European Commission are always about dimensions such as \% of spending or targeted users. Indeed, the impact occurs much later, and accounting for a part of the funding of the program would be more complicated. (Education and Training DG)

Two DGs (Mobility and Infrastructure, Health and Welfare) present a more sophisticated profile in measurement, with a process of internal legitimization of indicators and targets (see the section on Goal autonomy). In the case of the Welfare and Health DG, for instance, the related Regional Health System adopts a consolidated benchmarking approach, based on the active involvement of both top management and professionals in the definition and refinement of indicators (Nuti et al., 2013), as well as prioritization (Nuti et al., 2017).

Overall, however, the analysis of programming official documents suggests a general image of the technicality of measurement, with several traits that can be referred to as a "logic of escalation" (Pollitt, 2013; Pollitt et al., 2010), that is the tendency for performance measurement systems to become increasingly expansive and technically complex.

\section{Incentives}

According to the dominant model across public organizations (Jakobsen et al., 2017), the incentives in most of the considered DGs reflect features that can be reconciled with the EA regime. Incentives relate to response schemes (positive or negative) considering the 
achievement of "external/hierarchical" goals based on the quantification of activities and procedures. The monitoring system, implemented by the Organization and Human Resources DG, provides a rewarding scheme that uses different weights and thresholds, in terms of target achievement, for managers and employees:

Within a framework of 140 expected results, [...] we identify an average value for the achievement of the annual strategic objectives to which an incentive scheme is anchored. This part of the reward is greater the smaller the hierarchical role played in the organization [the reverse criterion is valid for the calculation of individual objectives]. [...] The Regional Executive gives an assessment where $70 \%$ achievement of the goals, i.e. the threshold, triggers the reward. For directors and managers, reaching this threshold is binding, whereas for the rest of the employees, the bonuses were awarded even if the goals were assessed as sufficient. (Organization and Human Resources DG)

However, the Welfare and Health DG emerged as an example of IL regime, where incentives are less externally driven and more aimed at norms, values and peer status. The profile of the DG is characterized by the extensive involvement of professionals in interpreting the goals set by the political and top management levels, and is in line with the contemporary dominant regime in welfare and healthcare policies (Jakobsen et al., 2017), which entails managing high task complexity and supporting autonomous motivation.

\section{Incorporation}

In the information-decision continuum, whereas measurement feeds the supply side and envisaged use is the demand side, incorporation aims to bring the two together (Van Dooren et al., 2015). In our analysis, the shape of this link is highly variable: in some DGs (Agriculture, Land use and Civil Protection), though there is systematic administration of data, the level of incorporation is limited and mostly formal and procedural, thus not necessarily supporting the decision-making process. On the other side, the interview with key informants of the Agriculture DG highlighted the connection between measurement and programming decisions:

During numerous interviews with the beneficiaries of the RDPs [Rural Development Plan], some results were incorporated into the planning process. (Agriculture DG)

Some other DGs adopt fluctuating forms of connection between measures and programming decisions, usually based on the individual feelings and experiences of the management:

We found ourselves with an existing programming process that had been defined top-down. [...] For us, the definition of goals is the responsibility of the General Manager and is based on previous trends. The individual goals, however, depend not only on the will of the General Manager but also on the goals of the PRS [Regional Development Plan] assigned to the DG. (Production DG)

Although the Regional Development Plan (PRS) formally states common strategic goals cross-cutting organizational boundaries, the substantive incorporation of these goals into performance routines in the DGs is quite weak. The financial (budgetary) dimension seems to be the only real overarching boundary transcending organizational specificities.

Use

Use appears more fragmented compared to the other dimensions. This variability is more influenced by the mission and the specific activity of each DG rather than by organizational factors. Thus, all four different ideal types proposed by Bouckaert and Halligan (2007) can be identified within the Regional Authority. The impossibility of assessing long-term impacts and foreseeing extraordinary events, as well as the strong relation with the 
European funding programmes, are some of the reasons why we classified the Agriculture DG and Land use and civil protection DG as examples of Performance Administration:

[The interviewee is describing the construction of a flood detention basin] The planning activity led to very limited benefits because these benefits have to be measured over a period of 200 years, with very little return in the short term. (Land Use and Civil Protection DG)

The Labour DG and the Production DG have features that can be linked to the Management of Performances model, such as a disconnection in the use of performance information between the political and managerial levels:

The Performance Plan is managed basically in the same way for all policy fields: but you can't apply the same criteria to someone who deals with incentives to enterprises, to one who makes bridges and to one who carries out environmental reclamation. But this approach comes from the directives of the Government. [...] To date [...] I still have no goals assigned. I should know the goals of the programming system at least in September, but so far I don't even know the amount of financial appropriations for next year. (Production DG)

This kind of disconnection is different from that related to the IL regime: the latter draws from a non-convergent use of performance information between the political and managerial levels (thus raising accountability risks), whereas this relates to the gaps in the cascade programming process, which leads to day-to-day micro-management orientation instead of strategizing.

Another large group of DGs reflects a more integrated profile, where performance information serves both the political sphere and the top management.

The Culture and Research DG is characterized by a proto-societal use of performance information. The need to monitor societal trends (.e.g. level of youth employment) and public opinion (e.g. through customer satisfaction surveys) drives the organization to reduce the distance between external stakeholders and internal activity:

The real problem is that we must also inform our stakeholders better about the service, because we are all busy working and very little time is spent in communication. (Culture and Research DG)

The use of performance information for EA has been also highlighted by the Labour DG as a key tool to inform and involve external stakeholders (e.g. citizens):

In order to make available for consultation by the stakeholders the progress of this specific project, twice a month we provide short reports on a dedicated website. (Labour DG)

\section{Rationale for improvement}

When considering the "doctrinal beliefs for how organizations improve" results (Jakobsen $e$ al., 2017, p. 7), most DGs reflect a "controlled motivation-driven" learning process (Jakobsen et al., 2017) that can be linked to the EA regime. This is based on the assumption that improvement occurs when external actors set the right incentives for the organization, the organizational learning process is fed by monitoring the level of goal achievement without exploring the underlying drivers. On the other hand, for some DGs (Welfare and Health, Territorial Planning and Social Housing, Environment and Energy) there appears to be a more circular learning approach, where encoding inferences from experience into organizational routines is not merely driven by external goals:

A methodology [for the analysis of local quality of life] was developed on the basis of various international benchmarks, with support from the Regional Institute for Economic Planning. A study was then carried out on current similar experiences in other parts of Europe. (Territorial Planning and Social Housing DG)

In these cases (which can be linked to $\mathrm{IL}$ regime), the values and experiences of experts or benchmarking processes tend to infuse external goal setting and form the basis for a double-loop 
learning dynamic. These emerging differences among DGs seem to correspond to sectoral and professional characteristics: indeed, the $\mathrm{IL}$ regime tends to emerge in more professionalized contexts, where knowledge-intensity (Von Nordenflycht, 2010) explains the need for an autonomy balance between professionals and managers. This need impacts on the level of participation in goal setting (see Goal autonomy) and role dynamics within the organization.
Analysis of PMSs for public organizations

\section{Discussion}

The analysis highlights some major trends and raises discussion points. Since both typologies (Bouckaert and Halligan, 2007; Jakobsen et al., 2017) cover a comprehensive range of possible models, the combination of the two should provide a complete matrix of "possible worlds" of PMSs (Figure 2), considering both objective and subjective dimensions. On the one hand, ideal types of managing performance range from a traditional model, which is connected to traditional public administration, to a performance governance one, which captures features that can be observed in most advanced public administration experiences today (Bryson and Crosby, 2014). On the other hand, performance regimes differentiate between traditional hierarchical functioning (EA regime) and professionalized functioning (professional regime), and in between, as a blurred combination of the two, is the IL regime.

However, the results of the analysis show a relatively concentrated distribution of DGs on the ideal types-regimes matrix. This means that, overall, the recurrent features of the regional authority across DGs systematically fail to fit with some models, namely performance governance and professional regime. Whereas the $\mathrm{IL}$ regime and performance management are loosely represented, the combination of EA regime with both performance administration and management of performances seems to be the rule.

The results also highlight a pronounced differentiation of PMSs themselves, both internally (by DGs, across different dimensions) and horizontally (by common dimensions, across different DGs). In an internal perspective, only two DGs seem to present features that are consistently reconcilable with a homogeneous model (performance administration combined with EA regime). In other cases, heterogeneity seems to relate to the evolution of models: organizational change, in this case, seems to occur by the incremental renewal of existing practices and tools, allowing for layering (Christensen and Lægreid, 2011), rather than by discontinuity and replacement. Horizontally, two dimensions tightly related to goal-setting process, namely goal autonomy and incentives, seem to be particularly homogeneous regardless of sectorial specificities. This can be

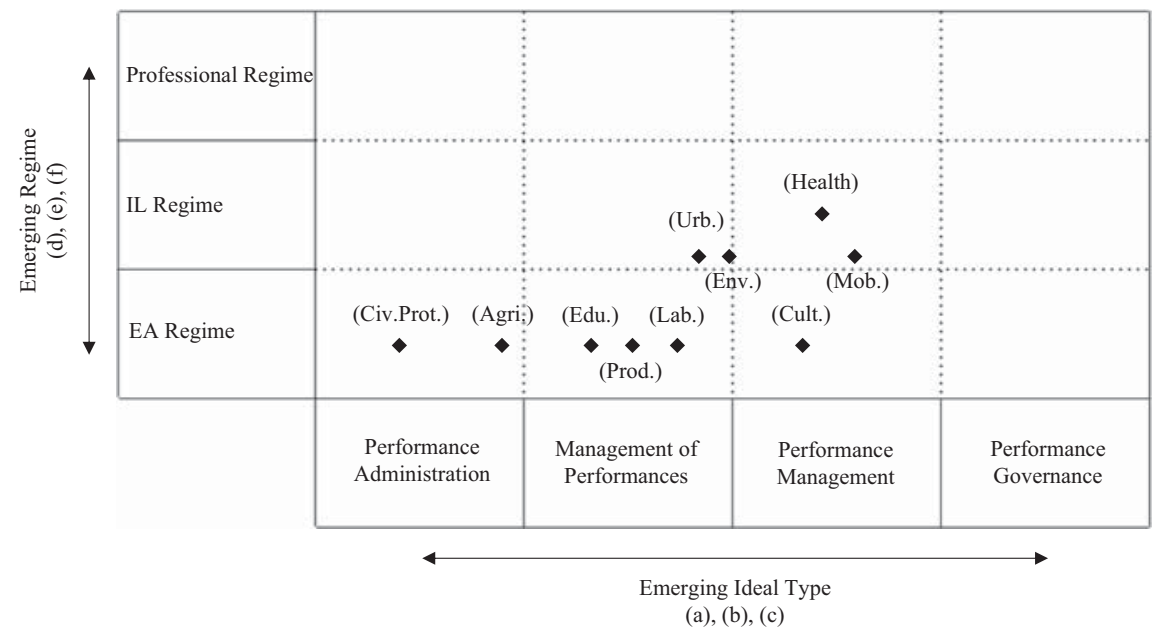

Figure 2.

Performance ideal types-regimes matrix 
read under the lens of governance isomorphic responses to crises (Lodge and Hood, 2012; Peters, 2011), as decentralized functions and decision-making processes tend to be taken back by the "holding" public body for the sake of control.

The positioning of the Health DG and the Mobility DG in the matrix suggests that, overall, they have implemented more advanced PMSs. This is linked to the different functions these DGs have in the regional system, compared to the others. In fact, Health and Mobility are in charge of both planning and managing the services (though provision might be delegated to other institutional entities), whereas the other DGs are mainly concerned with planning alone.

There are two main contributions of this study. From a theoretical standpoint, we develop, present and discuss a comprehensive framework of analysis combining ideal types of managing performance with performance regimes. To the best of our knowledge, this represents a first attempt to integrate both objective and subjective dimensions into a common framework of analysis for PMSs in the public sector. Regarding practice, we try to reveal patterns of differentiation of PMSs across parts of a common regional authority, through the aforementioned framework of analysis. This methodological lens can help public managers to analyse organizations' characteristics and identify structural and contingent factors, with the latter opening room for managerial interventions.

\section{Conclusions}

The complexity of governance tends to increase when moving away from traditional public administration towards networked systems (Moynihan et al., 2011). In fact, public organizations usually turn to networks to deal with "wicked problems" (Head and Alford, 2015) that go beyond the capacity of individual organizations. External complexity then gives rise to internal complexity, by introducing different sets of institutional and cultural tensions that can limit the functionality of standard organizational responses. This phenomenon can be observed also within a common institutional context, such as regional authorities governing a host of organizational units dealing with very different policy domains.

This study contributes to public management scholarship on complexity by exploring how layering affects mesostructures of public administration, namely PMSs. In fact, to the best of our knowledge, this study is the first attempt to reconcile ideal types of managing performance and performance regimes typologies, in order to provide an integrated framework of analysis on PMSs specifically devoted to the analysis of organizational complexity at the meso level in a public sector setting.

Given that layering is one of the reasons why complexity and hybridity develop in political-administrative systems (Christensen, 2013), this paper also highlights a promising avenue for future research. Hybridity addresses the potential tension and inconsistency between diverse structural and cultural elements in government (Christensen, 2013). In other words, compared to the descriptive nature of layering-oriented scholarship, a hybrid-based approach could reveal whether cultural and structural connotation primarily explain differences in the characteristics of public organizations.

Denis et al. (2015) grouped studies on hybridity in the public sector into three main streams: public sector reforms in a sectoral field, cross-sectorial studies (i.e. public-private relationships) and hybrid roles in public services. Though great attention has been devoted in public management scholarship to conceptualizing performance classification (Bouckaert and Halligan, 2007; Jakobsen et al., 2017), to the best of our knowledge this has not been discussed previously under the lenses of hybridity. The results of this study suggest that structural (e.g. technological) and cultural (e.g. professional) elements could explain the pattern of differentiation of PMSs across parts of a regional authority. Based on these insights and the aforementioned literature gap, further research on public administration hybridization at the meso level is much needed. 
A first limitation of the study draws from contingency. Since the paper reports the results from a specific regional context in a specific timeframe, the inherent institutional uncertainty under which the data were collected might affect our results: whereas some DGs were directly undergoing a process of institutional centralization, others were only experiencing the indirect effects of this process. This may have introduced a confounding factor that, due to data availability, could not be neutralized.

A second limitation of the study relates to the features of the considered frameworks of analysis. Both frameworks describe archetypal models which real world PMSs are expected to be interpreted by (not reconciled with). However, ideal types of performance (Bouckaert and Halligan, 2007) provide reference points (i.e. the key features of the framework) aiming to set a comprehensive taxonomy covering a broad range of possibilities. Performance regimes (Jakobsen et al., 2017), on the other hand, should be intended as the codification of some specific cases: therefore, it could be guessed that the latter classification may not be exhaustive per se and several more hybrid possibilities can be conceived.

Our results could be clearly dependent on the theoretical premises we adopted. Future research should then further develop performance regimes conceptualization, in order to extend its scope and provide scholars with more defined interpretative schemes. Future contributions could also extend this stream of research to other administrations that are experiencing a similar process of institutional redefinition, and account for the effects of institutional change in combination with PMSs composition.

\section{Acknowledgements}

The authors wish to thank all the researchers of the Health and Management (MeS) Lab and the Sustainability Management (SuM) group of the Institute of Management (Scuola Superiore Sant'Anna, Pisa) for their valuable support, and Professor Sabina Nuti (Scuola Superiore Sant'Anna, Pisa) as the scientific supervisor of the project from which the study originated, for her comments and suggestions on previous versions of the paper. The authors wish also to acknowledge the regional administrators and staff of the regional authority involved in the study for their precious collaboration.

\section{References}

Andrews, R. and Boyne, G.A. (2014), "Task complexity, organization size, and administrative intensity: the case of UK universities", Public Administration, Vol. 92 No. 3, pp. 656-672.

Annoni, P., Dijkstra, L. and Gargano, N. (2017), “The EU regional competitiveness Index 2016”, WP 02/2017, Directorate-General for Regional and Urban Policy, Brussels.

Bouckaert, G. and Halligan, J. (2007), Managing Performance: International Comparisons, Routledge, Abingdon, Oxon.

Bovaird, T. and Löffler, E. (2009), Public Management and Governance, Taylor \& Francis, New York, NY.

Brudan, A. (2010), "Rediscovering performance management: systems, learning and integration", Measuring Business Excellence, Vol. 14 No. 1, pp. 109-123, available at: https://doi.org/10.1108/13683041011027490

Bryson, J.M. and Crosby, B.C. (2014), "Public value governance: moving beyond traditional public administration and the new public management", Public Administration Review, Vol. 74 No. 4, pp. 445-456, available at: https://doi.org/10.1111/puar.12238.Public

Charron, N. and Lapuente, V. (2018), "Quality of government in EU regions: spatial and temporal patterns", QoG Working Paper Series, Department of Political Science, University of Gothenburg, p. 1.

Charron, N., Dijkstra, L. and Lapuente, V. (2014), "Regional governance matters: quality of government within European Union member states”, Regional Studies, Vol. 48 No. 1, pp. 68-90. 
Christensen, T. (2013), "New public management and beyond. the hybridization of public sector reforms", Global Themes and Local Variations in Organization and Management: Perspectives on Glocalization, Routledge, Abingdon, Oxon.

Christensen, T. and Lægreid, P. (2011), "Complexity and hybrid public administration-theoretical and empirical challenges", Public Organization Review, Vol. 11 No. 4, pp. 407-423.

De Bruijn, H. (2002), "Performance measurement in the public sector: strategies to cope with the risks of performance measurement", International Journal of Public Sector Management, Vol. 15 No. 7 , pp. 578-594, available at: https://doi.org/doi:10.1108/09513550210448607

Deci, E.L. and Ryan, R.M. (2000), "The 'what' and 'why' of goal pursuits: human needs and the self-determination of behavior”, Psychological Inquiry, Vol. 11 No. 4, pp. 227-268.

Denis, J.-L., Ferlie, E. and Van Gestel, N. (2015), “Understanding hybridity in public organizations”, Public Administration, Vol. 93 No. 2, pp. 273-289, available at: https://doi.org/10.1111/padm.12175

Denzin, N.K. and Lincoln, Y.S. (2005), "Introduction: the discipline and practice of qualitative research", The Sage Handbook of Qualitative Research, Sage Publications, Thousand Oaks, CA, pp. 1-32.

Dickinson, H., Bismark, M., Phelps, G. and Loh, E. (2016), "Future of medical engagement”, Australian Health Review, Vol. 40 No. 4, pp. 443-446.

Drechsler, W. (2010), "The re-emergence of 'Weberian' public administration after the fall of new public management: the central and eastern European perspective", Administrative Culture, Vol. 6 No. 1, pp. 94-108.

Dunleavy, P. and Hood, C. (1994), "From old public administration to new public management", Public Money and Management, Vol. 14 No. 3, pp. 9-16, available at: https://doi.org/10.1080/09540969409387823

Ferreira, A. and Otley, D. (2009), "The design and use of performance management systems: an extended framework for analysis", Management Accounting Research, Vol. 20 No. 4, pp. 263-282, available at: https://doi.org/10.1016/J.MAR.2009.07.003

Forsythe, D.W. (2001), "Pitfalls in designing and implementing performance management systems", in Forsythe, D. (Ed.), Quicker, Better, Cheaper: Managing Performance in American Government, Rockefeller Institute Press, Albany, NY, pp. 519-549.

Fryer, K., Antony, J. and Ogden, S. (2009), "Performance management in the public sector", International Journal of Public Sector Management, Vol. 22 No. 6, pp. 478-498, available at: https://doi.org/ $10.1108 / 09513550910982850$

Glaser, B.G. (1965), "The constant comparative method of qualitative analysis", Social Problems, Vol. 12 No. 4, pp. 436-445.

Graneheim, U.H. and Lundman, B. (2004), "Qualitative content analysis in nursing research: concepts, procedures and measures to achieve trustworthiness", Nurse Education Today, Vol. 24 No. 2, pp. 105-112.

Greiling, D. and Halachmi, A. (2013), "Accountability and organizational learning in the public sector", Public Performance and Management Review, Vol. 36 No. 3, pp. 380-406.

Head, B.W. and Alford, J. (2015), "Wicked problems: implications for public policy and management", Administration and Society, Vol. 47 No. 6, pp. 711-739, available at: https://doi.org/10.1177/ 0095399713481601

Iacovino, N.M., Barsanti, S. and Cinquini, L. (2015), "Public organizations between old public administration, new public management and public governance: the case of the Tuscany region", Public Organization Review, Vol. 17 No. 1, pp. 61-82, available at: https://doi.org/10.1007/ s11115-015-0327-x

Jakobsen, M.L., Baekgaard, M., Moynihan, D.P. and Van Loon, N.M. (2017), "Making sense of performance regimes: rebalancing external accountability and internal learning", Perspectives on Public Management and Governance, Vol. 1 No. 2, pp. 127-141, available at: https://doi.org/10.1093/ppmgov/gvx001

Ketelaar, A., Manning, N. and Turkisch, E. (2007), "Performance-based arrangements for senior civil servants OECD and other country experiences", OECD working papers on public governance, OECD Publishing, Paris. 
Krippendorff, K. (2012), Content Analysis: An Introduction to its Methodology, Sage Publications, Thousand Oaks, CA.

Kroll, A. (2015), "Drivers of performance information use: systematic literature review and directions for future research", Public Performance and Management Review, Vol. 38 No. 3, pp. 459-486, available at: https://doi.org/10.1080/15309576.2015.1006469

Lee Rhodes, M., Biondi, L., Gomes, R., Melo, A.I., Ohemeng, F., Perez-Lopez, G., Rossi, A. and Sutiyono, W. (2012), "Current state of public sector performance management in seven selected countries", International Journal of Productivity and Performance Management, Vol. 61 No. 3, pp. 235-271, available at: https://doi.org/10.1108/17410401211205632

Liguori, M., Steccolini, I. and Rota, S. (2016), "Studying administrative reforms through textual analysis: the case of Italian central government accounting", International Review of Administrative Sciences, Vol. 84 No. 2, pp. 308-333, available at: https://doi.org/10.1177/0020852315619023

Locke, C. and Lloyd-Sherlock, P. (2011), "Qualitative life course methodologies: critical reflections from development studies”, Development and Change, Vol. 42 No. 5, pp. 1131-1152.

Lodge, M. and Hood, C. (2012), "Into an age of multiple austerities? public management and public service bargains across OECD countries", Governance, Vol. 25 No. 1, pp. 79-101.

Malmi, T. and Brown, D.A. (2008), "Management control systems as a package-Opportunities, challenges and research directions", Management Accounting Research, Vol. 19 No. 4, pp. 287-300, available at: https://doi.org/10.1016/j.mar.2008.09.003

Mintzberg, H. (1989), “The structuring of organizations”, Readings in Strategic Management, Palgrave, London, pp. 322-352.

Morgan, G. and Smircich, L. (1980), "The case for qualitative research", Academy of Management Review, Vol. 5 No. 4, pp. 491-500.

Moynihan, D.P. (2008), The Dynamics of Performance Management: Constructing Information and Reform, Georgetown University Press, Washington, DC.

Moynihan, D.P. and Pandey, S.K. (2010), "The big question for performance management: why do managers use performance information?", Journal of Public Administration Research and Theory, Vol. 20 No. 4, pp. 849-866, available at: https://doi.org/10.1093/jopart/muq004

Moynihan, D.P., Fernandez, S., Kim, S., Leroux, K.M., Piotrowski, S.J., Wright, B.E. and Yang, K. (2011), "Performance regimes amidst governance complexity", Journal of Public Administration Research and Theory, Vol. 21, pp. 141-155, available at: https://doi.org/10.1093/jopart/muq059

Newcomer, K. and Caudle, S. (2011), "Public performance management systems. embedding practices for improved success", Public Performance and Management Review, Vol. 35 No. 1, pp. 108-132, available at: https://doi.org/10.2753/PMR1530-9576350106

Nuti, S., Seghieri, C. and Vainieri, M. (2013), "Assessing the effectiveness of a performance evaluation system in the public health care sector: some novel evidence from the Tuscany region experience", Journal of Management and Governance, Vol. 17 No. 1, pp. 59-69, available at: https://oi.org/10.1007/ s10997-012-9218-5

Nuti, S., Vainieri, M. and Vola, F. (2017), "Priorities and targets: supporting target-setting in healthcare", Public Money and Management, Vol. 37 No. 4, pp. 277-284, available at: https://doi.org/10.1080/ 09540962.2017.1295728

Ohemeng, F. (2010), "The dangers of internationalization and 'one-size-fits-all' in public sector management", International Journal of Public Sector Management, Vol. 23 No. 5, pp. 456-478, available at: https://doi.org/10.1108/09513551011058484

Ongaro, E. and Valotti, G. (2008), "Public management reform in Italy: explaining the implementation gap", International Journal of Public Sector Management, Vol. 21 No. 2, pp. 174-204, available at: https:/doi. org/10.1108/09513550810855654

O'Toole, L.J. and Meier, K.J. (2015), "Public management, context, and performance: in quest of a more general theory", Journal of Public Administration Research and Theory, Vol. 25 No. 1, pp. 237-256, available at: https://doi.org/10.1093/jopart/muu011 
Peters, B.G. (2011), "Governance responses to the fiscal crisis-comparative perspectives”, Public Money and Management, Vol. 31, pp. 75-80, available at: https://doi.org/10.1080/09540962.2011.545551

Pollitt, C. (2013), "The logics of performance management", Evaluation, Vol. 19, pp. 346-363, available at: https://doi.org/10.1177/1356389013505040

Pollitt, C. and Bouckaert, G. (2011), Public Management Reform: A comparative Analysis-new Public Management, Governance, and the Neo-Weberian State, Oxford University Press, Oxford.

Pollitt, C., Harrison, S., Dowswell, G., Jerak-Zuiderent, S. and Bal, R. (2010), "Performance regimes in health care: institutions, critical junctures and the logic of escalation in England and the Netherlands", Evaluation, Vol. 16 No. 1, pp. 13-29, available at: https://doi.org/10.1177/1356389009350026

Saunila, M., Tikkamäki, K. and Ukko, J. (2015), "Managing performance and learning through reflective practices", Journal of Organizational Effectiveness: People and Performance, Vol. 2 No. 4, pp. 370-390.

Starman, A.B. (2013), "The case study as a type of qualitative research", Journal of Contemporary Medical Education Studies, Vol. 64 No. 1, pp. 28-43.

Talbot, C. (2008), "Performance regimes - the institutional context of performance policies", International Journal of Public Administration, Vol. 31 No. 14, pp. 1569-1591, available at: https://doi.org/ 10.1080/01900690802199437

Taylor, S.J., Bogdan, R. and DeVault, M. (2015), Introduction to Qualitative Research Methods: A Guidebook and Resource, John Wiley \& Sons, Hoboken, NJ.

Vainieri, M., Ferrè, F., Giacomelli, G. and Nuti, S. (2019), "Explaining performance in health care: how and when top management competencies make the difference", Health Care Management Review, Vol. 44 No. 4, pp. 306-317, available at: https://doi.org/10.1097/HMR.00000000000000164

Van Dooren, W. and Van de Walle, S. (2016), Performance Information in the Public Sector: How it is Used, Springer.

Van Dooren, W., Bouckaert, G. and Halligan, J. (2015), Performance Management in the Public Sector, Routledge, Abingdon, Oxon.

Van Loon, N.M. and Jakobsen, M.L. (2018), "Connecting governance and the front lines: how work pressure and autonomy matter for coping in different performance regimes", Public Administration, Vol. 96 No. 3, pp. 435-451, available at: https://doi.org/10.1111/padm.12357

Van Thiel, S. and Leeuw, F.L. (2002), "The performance paradox in the public sector", Public Performance and Management Review, Vol. 25 No. 3, pp. 267-281, available at: https://doi.org/10.2307/3381236

Von Nordenflycht, A. (2010), "What is a professional service firm? Toward a theory and taxonomy of knowledge-intensive firms", Academy of Management Review, Vol. 35 No. 1, pp. 155-174.

Wholey, J.S. (2002), "Making results count in public and nonprofit organizations: balancing performance with other values", in Newcomer, K., Jennings, E.T. Jr, Broome, C. and Lomax, A. (Eds), Meeting the Challenges of Performance-Oriented Government, American Society for Public Administration, Washington, DC, pp. 13-35.

Yin, R.K. (2017), Case Study Research and Applications: Design and Methods, Sage Publications, Thousand Oaks, CA.

\section{Corresponding author}

Giorgio Giacomelli can be contacted at: g.giacomelli@santannapisa.it 


\section{Appendix}

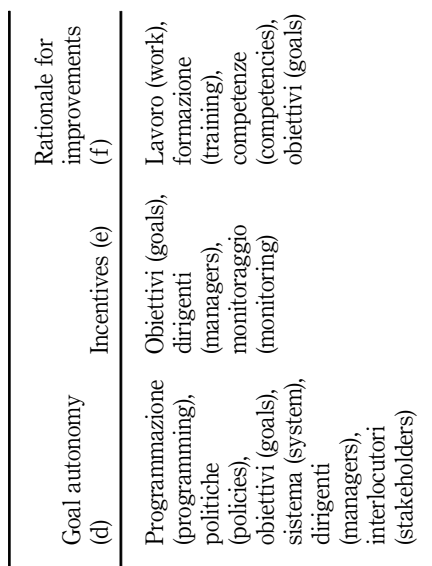

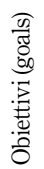

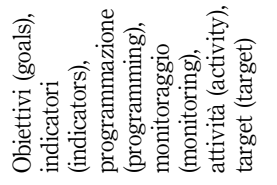

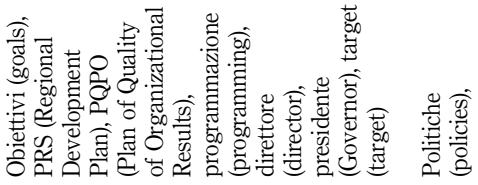

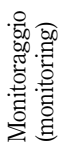

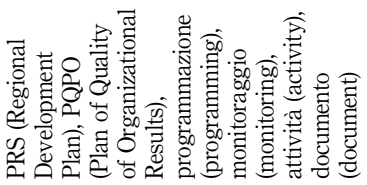

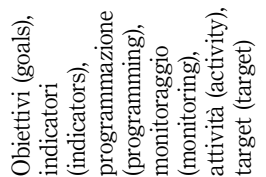

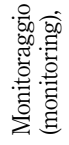

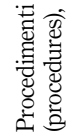

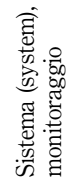

Analysis of

PMSs for public organizations

\section{के}

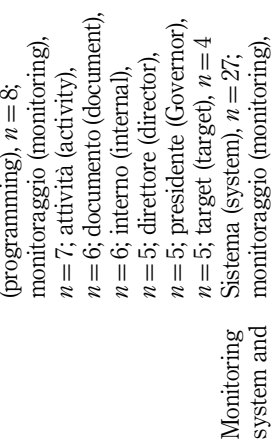

Table A1

Frequent words and additional keywords considered for textual analysis of the interviews 


\section{IJPSM}

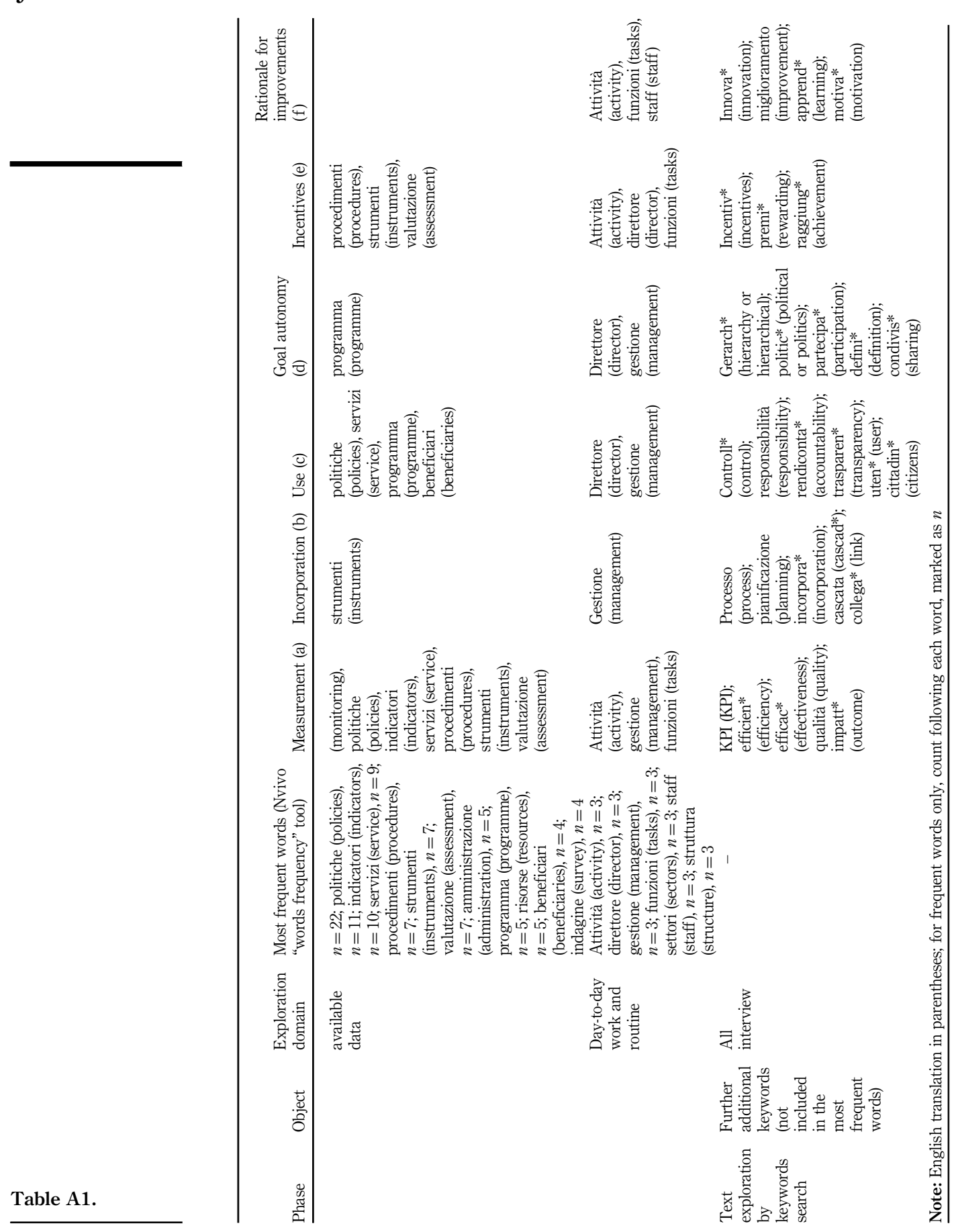

